ORIGINAL RESEARCH

\title{
National Estimates of Noncanine Bite and Sting Injuries Treated in US Hospital Emergency Departments, 2001-2010
}

\author{
Ricky Langley, MD, MPH; Karin Mack, PhD; Tadesse Haileyesus, MS; Scott Proescholdbell, MPH; \\ Joseph L. Annest, PhD \\ From the North Carolina Department of Health and Human Services, Raleigh, NC (Dr Langley and Mr Proescholdbell); and the National Center \\ for Injury Prevention and Control, Centers for Disease Control and Prevention, Atlanta, GA (Drs Mack and Annest, Mr Haileyesus).
}

Objective.--Injuries resulting from contact with animals and insects are a significant public health concern. This study quantifies nonfatal bite and sting injuries by noncanine sources using data from the National Electronic Injury Surveillance System-All Injury Program (NEISS-AIP).

Methods. - The NEISS-AIP is an ongoing nationally representative surveillance system used to monitor all types and causes of injuries treated in US hospital emergency departments (EDs). Cases were coded by trained hospital coders using information from medical records on animal and insect sources of bite and sting injuries being treated. Data were weighted to produce national annualized estimates, percentages, and rates based on the US population.

Results.-From 2001 to 2010 an estimated 10.1 million people visited EDs for noncanine bite and sting injuries, based on an unweighted case count of 169,010 . This translates to a rate of 340.1 per 100,000 people (95\% CI, 232.9-447.3). Insects accounted for 67.5\% (95\% CI, 45.8-89.2) of bite and sting injuries, followed by arachnids $20.8 \%$ (95\% CI, 13.8-27.9). The estimated number of ED visits for bedbug bite injuries increased more than 7-fold-from 2156 visits in 2007 to 15,945 visits in 2010.

Conclusions.- This study provides an update of national estimates of noncanine bite and sting injuries and describes the diversity of animal exposures based on a national sample of EDs. Treatment of nonfatal bite and sting injuries are costly to society. Direct medical and work time lost translates to an estimated $\$ 7.5$ billion annually.

Key words: insect, wasps, hornet, bee, ant, arachnid, reptile, snake, stings, bites, emergency

\section{Introduction}

Despite numerous recommendations from both the medical and veterinary professions, injuries resulting from contact with animals remain a significant public health concern. ${ }^{1-3}$ Animals can bite, sting, scratch, peck, maul, trample, fall on, throw off riders, crush, or gore. Even excluding infections and allergies resulting from exposure to animals, millions of individuals still suffer injuries from adverse encounters with animals in the United States resulting in pain, tissue damage, disability,

Disclaimer: The findings and conclusions in this report are those of the authors and do not necessarily represent the views of the CDC. The authors have no financial disclosures or conflicts of interest to declare.

Corresponding author: Ricky Langley, MD, MPH, North Carolina Division of Public Health, Raleigh, NC 27699-1912 (e-mail: Rick. langley@dhhs.nc.gov). and even death. Although canine injuries have probably been the best documented, with an estimated 4 million persons reporting injuries per year, numerous other species cause human injury. ${ }^{4}$

Nonfatal bites and stings account for a substantial proportion of injuries from contact with animals. There have been a few national studies on the occurrence of nonfatal animal bites, primarily canine. ${ }^{4-6}$ A recent study found an average of 323,000 dog bites treated in US hospital emergency departments (EDs) from 2005 to $2009,^{7}$ and another national study from 2001 to 2006 found that dogs and cats were responsible for an annual average of 86,629 nonfatal falls. ${ }^{8}$ The American Association of Poison Control Centers reports on calls regarding animal exposures, and in a study from 2001 to 2005, an annual average of 94,552 calls were made to poison control centers for animal exposures. ${ }^{9}$ 
Additionally, there have been national studies on deaths from animal injuries. In recent reviews of US deaths from animal encounters, an average of 177 deaths per year were reported from animal encounters from 1991 to 2001, which increased slightly to 200 average annual deaths during the period 1999 to $2008 .^{10,11}$

A few national studies have focused on noncanine bite and sting injury-related ED visits or hospitalizations. In a study using the Agency for Healthcare Research and Quality data on nationwide ED visits and community hospital discharges from 2006 to 2008, an annual average of 1 million ED visits and nearly 50,000 hospitalizations were reported. ${ }^{12}$ That study, however, lacked detailed information on the type of animal species involved in the encounter. In comparison, O'Neil et $\mathrm{al}^{13}$ provided much more detailed epidemiologic information on the species of noncanine animal bites and stings resulting in a visit to the ED. Based on their study, with data from 2001 to 2004, an estimated 900,000 people were treated in US hospital EDs annually for noncanine bite and sting injuries. ${ }^{13}$ The current study provides an update to the work of O'Neil et al using more current data from the National Electronic Injury Surveillance System-All Injury Program (NEISS-AIP).

\section{Methods}

\section{STUDY DESIGN AND SETTING}

The National Electronic Injury Surveillance System (NEISS) is an ongoing surveillance system used to monitor consumer product-related injuries treated in US hospital EDs. The system is maintained and operated by the US Consumer Product Safety Commission (CPSC). There are currently 99 NEISS hospital EDs, which represent a stratified probability sample of all US and US territory hospitals that have at least 6 beds and provide 24-hour emergency services. The sample includes 5 strata, including 4 strata based on size (very large, large, medium, and small defined by the number of hospital ED visits annually) and 1 stratum for children's hospitals. The NEISS collects data only on the initial ED visit for an injury incident and is particularly sensitive for detecting emerging injury problems. The NEISS-AIP collects data from a nationally representative subsample of 66 NEISS hospitals. The NEISS-AIP tracks all types and causes of nonfatal injuries seen in EDs whether or not they are associated with consumer products. For this project, NEISS-AIP data were analyzed for a 10-year period from 2001 through 2010. The NEISS-AIP is a collaborative effort of the Centers for Disease Control and Prevention's (CDC's) National Center for Injury Prevention and Control (Injury Center) and the CPSC, and has been described in more detail in previously published reports. ${ }^{13,14}$

For each case, NEISS hospital coders collected the following information from the ED medical record: age, sex, injury diagnosis, body part injured, ED discharge disposition, locale where the injury occurred (eg, home, street/highway), work-relatedness, and intentionality (ie, unintentional, assault, suicide attempt, or unknown intent) of the injury event. In addition, a 2-line narrative describing circumstance and treatment of injuries was recorded based on text in the medical record. For this study, cases were defined as people treated at an NEISSAIP hospital for a bite or sting injury and were included if intent was coded as unintentional. Those who were dead on arrival or who died in the ED were excluded because these deaths are not fully captured by the NEISS-AIP. Dog and human bites and bites or stings incurred at work or during active military duty were excluded from these analyses. Dog bites have been addressed in other recent reports. ${ }^{15}$ Human bites were excluded because most were assault-related. Workrelated bites and stings were excluded because risk, exposure, and prevention are different from that of the general population and would most likely involve onthe-job safety precautions.

The ED discharge disposition included 6 possible categories: treated and released, transferred to another facility for specialized care (eg, trauma center), hospitalized, observed (ie, held for observation), left without being seen, or unknown. Given the small number of cases in the latter 3 categories, they were combined in the analyses. Cases that were transferred were combined with cases that were hospitalized in the NEISS-AIP and are referred to in the text as hospitalized.

\section{CLASSIFICATION OF STUDY CASES BY SOURCE}

Cases were initially classified hierarchically by broader species categories and for specific types of species, using computer programs to conduct keyword searches (including misspellings) of the narrative for each NEISS-AIP case. The initial assignment along with the narrative description for each nonfatal bite and sting case was then visually reviewed independently by 2 study researchers to confirm the accuracy of classification. Discrepancies in classification of NEISS-AIP cases among reviewers were then resolved by discussion and consensus.

\section{DATA ANALYSIS}

National annual estimates and percentages were based on weighted data. A sample weight was calculated by the CPSC for each injured person treated at an NEISS-AIP 
hospital on the basis of the inverse of the probability of selection of that hospital in each stratum. In addition, sample weights were adjusted for nonresponse and poststratified to account for changes in the annual number of ED visits over time. The poststratification adjustment applied to the basic NEISS-AIP weight was the ratio of the known total number of ED visits in the population (from the most recent hospital database) over the estimate of the total ED visits based on the sample of NEISS-AIP hospitals. ${ }^{16}$ Rates per 100,000 persons were calculated using US Census Bureau bridged race population estimates available on the Web-based Injury Statistics Query and Reporting System (WISQARS). ${ }^{17}$ Injury estimates were identified as unstable if the number of sample cases was less than 20 , the weighted estimate was less than 1200 , or the coefficient of variation (CV) was greater than 30. Analyses were conducted using SAS 9.3 (SAS Institute, Inc, Cary, NC), and 95\% CIs and statistical tests accounted for the sample weights and the complex survey design.

\section{COST ESTIMATION}

The total lifetime medical and work loss costs and combined (medical plus work loss) costs for unintentional canine and noncanine bites and stings were estimated using WISQARS. ${ }^{17}$ The WISQARS Cost of Injury Reports computes the cost of hospitalizations (including those hospitalized and transferred for specialized care) and of ED visits for those treated and released without hospitalization. Cost estimates for 2010 were computed based on 2005 average medical and work loss costs provided by WISQARS that were adjusted to 2010 prices.

\section{Results}

From 2001 through 2010, an estimated 10,101,320 (95\% CI, 6,917,902-13,284,737) people visited US EDs for noncanine bite and sting injuries, based on a total unweighted case count of 169,010 ED visits (Table 1). This translates into an average annual estimate of 1,010,132 ED visits with $96.4 \%$ (95\% CI, 66.2-126.6) being treated and released. An estimated $1.82 \%$ (95\% CI, 1.1-2.5) of the cases required hospitalization, and the remaining $1.8 \%$ (95\% CI, 1.0-2.7) were observed or left before being seen by physicians or had an unknown disposition. The crude rate of bite and sting injuries was 340.1 (95\% CI, 232.9-447.3) per 100,000 persons per year. The bite and sting injury rate was highest for children (751.8 per 100,000; 95\% CI, 491.9-1012.0) for the 0 - to 4-year-old age group, and 460.8 per 100,000 (95\% CI, 306.9-614.6) for the 5- to 9-year-old age group). Overall the crude rate was similar for males and females (345.8 per 100,000; 95\% CI, 235.7-455.9 for males; 334.5 per 100,000; 95\% CI, 229.4-439.6 for females).

Bite and sting injuries were most likely to occur to the extremities, predominantly to the arms or hands $33.6 \%$ (95\% CI, 23.0-44.2) followed by those to the leg or foot $27.5 \%$ (95\% CI, 18.1-37.0). The majority (59\%; $95 \%$ CI, 41-77) of the bite and sting injuries occurred during the summer season with injuries in July and August accounting for $33.6 \%$ (95\% CI, 23.3-43.7) of the total cases for the year. The lowest percentage of bite or sting injuries occurred during the month of February (2.6\%; 95\% CI, 1.5-3.7).

National estimates of noncanine bite and sting injuries treated in hospital EDs varied substantially by source (Table 2). The source of the bite or sting injury was most frequently an insect (67.5\%; 95\% CI, 45.8-89.2). Of the insect category, $63.3 \%$ were classified as an unspecified insect and $32.5 \%$ were hymenoptera. Arachnids were responsible for $20.8 \%$ (95\% CI, 13.8-27.9) of the injuries with spiders being responsible for $67.9 \%$ of the arachnid encounters. A venomous spider (black widow, brown recluse, other toxic) was indicated in $2.2 \%$ of arachnid cases. Of the mammal-related injuries, an estimated 70,253 (95\% CI, 46,601-93,906) injuries resulted from encounters with cats, 13,707 (95\% CI, 7780-19,634) injured persons were bitten by rodents annually. About half of marine-related injuries were attributable to stingrays. Regarding reptiles, snakebite was recorded as the source of injury for 9165 (95\% CI, 5772-12,558) cases annually of which $69.2 \%$ were nonvenomous or unknown type of snake.

The number and percentage of nonfatal bite and sting injuries for arachnids, insects, and reptiles varied substantially by year of treatment (Table 3 , Figure). Annual number of nonfatal bite and sting injuries ranges from 135,202 to 255,495 for arachnids, 575,526 to 778,953 for insects, and 7406 to 13,062 for reptiles during the study period. Although toxic spider bite injuries declined $44 \%$, tick bite injuries increased by $78 \%$ from 2001 to 2010. Most notable was the 7.4-fold increase in the estimated number of bedbug bite injuries from 2007 to 2010 .

\section{Discussion}

Noncanine animal-related bite and sting injuries have considerable impact on our society. Most previous reports of animal-related injuries focus on a specific population, regional geographic area, or specific animal. This study provides an update of national estimates of noncanine bite or sting injuries and describes the diversity of the animal exposures based on a nationally 
Table 1. Annual national estimates, percentages, and rates of nonfatal unintentional bite and sting injuries ${ }^{\mathrm{a}}$ treated in emergency departments, by selected characteristics, United States, 2001-2010

\begin{tabular}{|c|c|c|c|}
\hline Characteristic & Weighted annualized estimate & Percent $(95 \%$ CI) & Rate $^{l}$ \\
\hline Total & $1,010,132$ & $100.0(68.5-131.5)$ & 340.1 \\
\hline \multicolumn{4}{|l|}{ Age (years) } \\
\hline $0-4$ & 149,457 & $14.8(9.7-19.9)$ & 751.8 \\
\hline $5-9$ & 91,336 & $9.0(6.0-12.1)$ & 460.8 \\
\hline $10-14$ & 60,942 & $6.0(4.1-7.9)$ & 289.9 \\
\hline $15-19$ & 75,381 & $7.5(5.1-9.9)$ & 351.0 \\
\hline $20-24$ & 93,495 & $9.3(6.1-12.4)$ & 448.1 \\
\hline $25-34$ & 149,036 & $14.8(9.9-19.6)$ & 374.8 \\
\hline $35-44$ & 134,281 & $13.3(8.9-17.7)$ & 310.9 \\
\hline $45-54$ & 114,683 & $11.4(7.7-15.0)$ & 269.3 \\
\hline $55-64$ & 42,744 & $4.2(2.8-5.6)$ & 219.0 \\
\hline $75+$ & 29,811 & $3.0(1.9-4.0)$ & 167.5 \\
\hline \multicolumn{4}{|l|}{ Sex } \\
\hline Male & 504,709 & $50.0(34.1-65.9)$ & 345.8 \\
\hline Female & 505,327 & $50.0(34.3-65.7)$ & 334.5 \\
\hline \multicolumn{4}{|l|}{ ED disposition } \\
\hline Treated and released & 973,654 & $96.4(66.2-126.6)$ & 327.8 \\
\hline Hospitalized/transferred & 18,121 & $1.8(1.1-2.5)$ & 6.1 \\
\hline Other/unknown & 18,357 & $1.8(1.0-2.7)$ & 6.2 \\
\hline \multicolumn{4}{|l|}{ Primary body part affected } \\
\hline Head/neck & 176,326 & $17.5(12.0-22.9)$ & 59.4 \\
\hline Trunk & 129,199 & $12.8(8.6-17.0)$ & 43.5 \\
\hline Arm/hand & 339,413 & $33.6(23.0-44.2)$ & 114.3 \\
\hline Leg/foot & 278,224 & $27.5(18.1-37.0)$ & 93.7 \\
\hline Other/unknown & 86,970 & $8.6(4.7-12.6)$ & 29.3 \\
\hline \multicolumn{4}{|l|}{ Month of ED visit } \\
\hline January & 28,226 & $2.8(1.6-4.0)$ & 114.0 \\
\hline February & 26,360 & $2.6(1.5-3.7)$ & 106.5 \\
\hline March & 38,499 & $3.8(2.3-5.3)$ & 155.5 \\
\hline April & 58,484 & $5.8(3.8-7.8)$ & 236.3 \\
\hline May & 90,327 & $8.9(6.1-1.8$ & 364.9 \\
\hline June & 128,302 & $12.7(8.9-6.5)$ & 518.3 \\
\hline July & 169,553 & $16.8(11.7-21.8)$ & 685.0 \\
\hline August & 169,214 & $16.8(11.6-21.9)$ & 683.6 \\
\hline September & 128,116 & $12.7(8.8-16.6)$ & 517.6 \\
\hline October & 84,461 & $8.4(5.5-11.2)$ & 341.2 \\
\hline November & 54,749 & $5.4(3.4-7.4)$ & 221.2 \\
\hline December & 33,840 & $3.4(2.0-4.7)$ & 136.7 \\
\hline
\end{tabular}

${ }^{a}$ Excludes canine, human, and work-related bite or sting injuries.

${ }^{b}$ Crude rate per 100,000 population.

representative sample of injured persons treated in US hospital EDs. ${ }^{13}$

Results of this study indicate that, nationally, slightly more than 1 million people were treated in EDs annually for injuries related to noncanine bites and stings. In addition, it is estimated that approximately 310,000 to 323,000 persons are treated annually in US EDs for a dog bite. ${ }^{7,12}$ This equates to 2.5 bite or sting injuries treated in US EDs every minute. This number does not include injuries treated outside the ED by other healthcare providers or those self-treated or not receiving any medical attention. Noncanine bites and stings were the seventh leading cause of ED visits for all age groups and the third leading cause for children younger than 1 to 4 years of age from 2001 to $2011 .{ }^{17}$ In addition to bite and sting injuries, an estimated 86,629 fall injuries associated with cats and dogs are treated in US EDs annually, for an annual injury rate of 29.7 per 100,000 population. ${ }^{8}$ The 
Table 2. Weighted annual estimates of nonfatal unintentional bite and sting injuries ${ }^{\mathrm{a}}$ treated in emergency departments by specific sources, United States, 2001-2010

\begin{tabular}{|c|c|c|c|}
\hline Source & $\begin{array}{c}\text { Weighted } \\
\text { annual estimate }^{b}\end{array}$ & Percent ${ }^{b}$ & $95 \% C^{c}$ \\
\hline Total & $1,010,132$ & 100.0 & $68.5-131.5$ \\
\hline Arachnid total & 210,454 & 20.8 & $13.8-27.9$ \\
\hline Scorpion & 7094 & 0.7 & $\ldots$ \\
\hline Spider total & 142,886 & 14.1 & $8.7-19.6$ \\
\hline Spider, other & 138,186 & 13.7 & $8.4-19.0$ \\
\hline Spider (toxic) total & 4700 & 0.5 & $0.2-0.7$ \\
\hline Black widow & 1075 & 0.1 & $0.0-0.2$ \\
\hline Brown recluse & 3565 & 0.4 & $0.2-0.5$ \\
\hline Other toxic ${ }^{d}$ & 60 & 0.0 & $\ldots$ \\
\hline Scabies & 341 & 0.0 & $0.0-0.1$ \\
\hline Tick & 59,879 & 5.9 & $3.0-8.9$ \\
\hline Other $\operatorname{arachnid}^{e}$ & 253 & 0.0 & $\ldots$ \\
\hline Bird total & 2206 & 0.2 & $0.1-0.3$ \\
\hline Parrot & 695 & 0.1 & $0.0-0.1$ \\
\hline Rooster & 263 & 0.0 & $0.0-0.0$ \\
\hline Other bird ${ }^{f}$ & 1248 & 0.1 & $0.1-0.2$ \\
\hline Insect total & 681,819 & 67.5 & $45.8-89.2$ \\
\hline Asp & 88 & 0.0 & \\
\hline Bedbug & 3304 & 0.3 & $0.1-0.5$ \\
\hline Caterpillar & 440 & 0.0 & $\ldots$ \\
\hline Chigger & 850 & 0.1 & $0.0-0.1$ \\
\hline Flea & 4266 & 0.4 & $0.3-0.6$ \\
\hline Fly & 1271 & 0.1 & $\ldots$ \\
\hline Hymenoptera total & 221,718 & 21.9 & $14.7-29.2$ \\
\hline Ant & 17,926 & 1.8 & $\ldots$ \\
\hline Bee & 162,080 & 16.0 & $10.5-21.6$ \\
\hline Other Hymenoptera ${ }^{g}$ & 1301 & 0.1 & $\ldots$ \\
\hline Vespid total & 40,412 & 4.0 & $2.6-5.4$ \\
\hline Hornet & 3774 & 0.4 & $0.2-0.5$ \\
\hline Wasp & 26,939 & 2.7 & $1.7-3.6$ \\
\hline Yellow jacket & 9134 & 0.9 & $0.5-1.3$ \\
\hline Other vespid $^{h}$ & 564 & 0.1 & $\ldots$ \\
\hline Insect (unspecified) & 431,356 & 42.7 & $27.7-57.7$ \\
\hline Kissing bug & 843 & 0.1 & $\ldots$ \\
\hline Mosquito & 16,281 & 1.6 & $1.0-2.3$ \\
\hline Other insect ${ }^{i}$ & 1402 & 0.1 & $0.1-0.2$ \\
\hline Mammal total & 93,400 & 9.2 & $6.1-12.4$ \\
\hline Bat & 1774 & 0.2 & $0.1-0.3$ \\
\hline Cat & 70,253 & 7.0 & $4.6-9.3$ \\
\hline Ferret & 328 & 0.0 & $0.0-0.0$ \\
\hline Horse & 1609 & 0.2 & $0.1-0.2$ \\
\hline Monkey & 161 & 0.0 & $0.0-0.0$ \\
\hline Opossum & 442 & 0.0 & $0.0-0.1$ \\
\hline Rabbit & 1095 & 0.1 & $0.1-0.1$ \\
\hline Raccoon & 1548 & 0.2 & $0.1-0.2$ \\
\hline Rodent total & 13,707 & 1.4 & $0.7-2.0$ \\
\hline Chipmunk & 227 & 0.0 & $0.0-0.0$ \\
\hline Gerbil & 134 & 0.0 & $0.0-0.0$ \\
\hline Guinea pig & 186 & 0.0 & $0.0-0.0$ \\
\hline Hamster & 1288 & 0.1 & $0.1-0.2$ \\
\hline Mouse & 3332 & 0.3 & $0.1-0.5$ \\
\hline
\end{tabular}


Table 2. Continued

\begin{tabular}{|c|c|c|c|}
\hline Source & $\begin{array}{c}\text { Weighted } \\
\text { annual estimate }^{b}\end{array}$ & Percent $^{b}$ & $95 \% C$ \\
\hline Rat & 4697 & 0.5 & $\ldots$ \\
\hline Squirrel & 2976 & 0.3 & $0.2-0.4$ \\
\hline Other rodent ${ }^{j}$ & 869 & 0.1 & $0.0-0.1$ \\
\hline Other mammal ${ }^{k}$ & 2484 & 0.2 & $0.2-0.3$ \\
\hline Marine total $^{c}$ & 4200 & 0.4 & $\ldots$ \\
\hline Fish & 627 & 0.1 & $0.0-0.1$ \\
\hline Jellyfish & 786 & 0.1 & $\ldots$ \\
\hline Stingray & 2150 & 0.2 & $\ldots$ \\
\hline Other marine $e^{l}$ & 638 & 0.1 & $\ldots$ \\
\hline Reptile total & 10,535 & 1.0 & $0.6-1.5$ \\
\hline Iguana & 810 & 0.1 & $0.0-0.1$ \\
\hline Snake total & 9165 & 0.9 & $0.5-1.3$ \\
\hline Snake (nonvenomous or unknown) & 6340 & 0.6 & $0.4-0.9$ \\
\hline Snake (venomous) total & 2825 & 0.3 & $\ldots$ \\
\hline Copperhead & 580 & 0.1 & $\ldots$ \\
\hline Rattlesnake & 1989 & 0.2 & $\ldots$ \\
\hline Other venomous $^{m}$ & 256 & 0.0 & $\ldots$ \\
\hline Turtle & 248 & 0.0 & $0.0-0.0$ \\
\hline Other reptile ${ }^{n}$ & 313 & 0.0 & $0.0-0.0$ \\
\hline Cross-category or unknown & 7518 & 0.7 & $0.4-1.1$ \\
\hline Insect and/or spider & 832 & 0.1 & $0.0-0.1$ \\
\hline Other cross-category $^{o}$ & 361 & 0.0 & $0.0-0.1$ \\
\hline Other specified $^{p}$ & 44 & 0.0 & $\ldots$ \\
\hline Unknown & 6282 & 0.6 & $0.3-0.9$ \\
\hline
\end{tabular}

${ }^{a}$ Excludes canine, human, and work-related bite and sting injuries.

${ }^{b}$ Values for groupings may not sum owing to rounding.

${ }^{c}$ Confidence intervals not provided where estimates might be unstable because the number of sample cases was $<20$, weighted estimate $<1200$, or coefficient of variation was $>30 \%$.

${ }^{d}$ Other toxic includes tarantulas or other unspecified toxic spider.

${ }^{e}$ Other arachnid includes dust mites, mites, and more than one arachnid source.

${ }^{f}$ Other bird includes chicken, cockatiel, cockatoo, duck, goose, macaw, parakeet, pigeon, seagull, turkey, and unspecified bird.

${ }^{g}$ Other hymenoptera includes more than one hymenoptera source.

${ }^{h}$ Other vespid includes more than one vespid source.

${ }^{i}$ Other insect includes centipede, cockroach, gnat, lice, no-see-um, pinworms, sand flea, and more than one insect source.

${ }^{j}$ Other rodent includes beaver, degu, gopher, groundhog, muskrat, porcupine, prairie dog, river rat, woodchuck, more than one rodent source, and unspecified rodent.

${ }^{k}$ Other mammal includes badger, bear, bobcat, bull, burro, camel, chinchilla, coati mundi, cow, coyote, deer, donkey, fox, goat, hedgehog, hog, javelina, llama, mink, mole, mountain lion, mule, otter, pig, polar bear, sea lion, seal, sheep, shrew, skunk, tiger, weasel, wolf, zebra, and unspecified animal.

${ }^{l}$ Other marine animal includes crab, eel, leech, lobster, sea anemone, sea urchin, shark, shellfish, starfish, zebra mussel, and unspecified marine organism.

${ }^{m}$ Other venomous snake includes cottonmouth, water moccasin, and unspecified venomous.

${ }^{n}$ Other reptile includes alligator, gecko, Gila monster, lizard, and unspecified reptile.

${ }^{\circ}$ Other cross-category includes more than one source that were cross species (eg, "flea and cat").

${ }^{p}$ Other specified includes worm or slug.

annualized rate of fall injuries from cat or dogs encounters was the highest in the elderly population (rates of $47.3,68.8,70.6$ per 100,000 for the $65-74$, $75-84$, and $>85$ age groups, respectively). ${ }^{8}$

Although insects and arachnids caused the majority of noncanine bite and sting injuries, contact with cats, gerbils, guinea pigs, hamsters, ferrets, and horses caused approximately $7.3 \%$ of noncanine ED visits. Recent surveys report that $56 \%$ to $62 \%$ of households own pets. ${ }^{18,19}$ The population of pets is reported to range from 81.7 million to 86.4 million cats, 69.9 to 78.2 million dogs, 4.9 to 7.9 million equine, and 8.3 to 16.2 
Table 3. Estimated national numbers and percentages of nonfatal unintentional bite and sting injuries treated in emergency departments by year and selected sources, United States, 2001-2010

\begin{tabular}{|c|c|c|c|c|c|}
\hline \multicolumn{6}{|c|}{ Arachnid } \\
\hline Year & $\begin{array}{l}\text { Spider (toxic) } \\
\text { number }(\%)\end{array}$ & $\begin{array}{l}\text { Other spider } \\
\text { number }(\%)\end{array}$ & Tick number (\%) & $\begin{array}{c}\text { Other arachnid } \\
\text { number }(\%)\end{array}$ & $\begin{array}{c}\text { Total arachnid } \\
\text { number (\%) }\end{array}$ \\
\hline 2001 & $5867(12.5)$ & $75,954(5.5)$ & $45,786(7.6)$ & 7594 (9.9) & $135,202(6.4)$ \\
\hline 2002 & $6151(13.1)$ & $81,165(5.9)$ & $40,663(6.8)$ & $9311(12.1)$ & $137,289(6.5)$ \\
\hline 2003 & $7559(16.1)$ & $128,660(9.3)$ & $62,518(10.4)$ & 8008 (10.4) & $206,744(9.8)$ \\
\hline 2004 & $5882(12.5)$ & $197,885(14.3)$ & $43,065(7.2)$ & 8663 (11.3) & $255,495(12.1)$ \\
\hline 2005 & $5527(11.8)$ & $183,166(13.3)$ & $46,684(7.8)$ & 8652 (11.3) & 244,029 (11.6) \\
\hline 2006 & $4274(9.1)$ & $168,148(12.2)$ & $53,738(9.0)$ & 8577 (11.2) & 234,737 (11.2) \\
\hline 2007 & $2755(5.9)$ & 160,339 (11.6) & $67,518(11.3)$ & $7207(9.4)$ & 237,819 (11.3) \\
\hline 2008 & $2666(5.7)$ & $134,063(9.7)$ & $68,490(11.4)$ & $4955(6.4)$ & $210,174(10.0)$ \\
\hline 2009 & $3038(6.5)$ & 122,707 (8.9) & 89,031 (14.9) & $6411(8.3)$ & $221,187(10.5)$ \\
\hline 2010 & $3281(7.0)^{a}$ & $129,776(9.4)$ & $81,300(13.6)$ & $7507(9.8)$ & $221,865(10.5)$ \\
\hline Total & $46,999(100)$ & $1,381,863(100)$ & $598,792(100)$ & 76,885 (100) & $2,104,539$ (100) \\
\hline
\end{tabular}

Insects

\begin{tabular}{crcccc}
\hline Year & Bedbug number (\%) & Bee number (\%) & Vespid number (\%) & Other insect number (\%) & Total insects number (\%) \\
\hline 2001 & $21(0.1)^{a}$ & $171,770(10.6)$ & $43,795(10.8)$ & $359,939(7.6)$ & $575,526(8.4)$ \\
2002 & $113(0.3)^{a}$ & $163,595(10.1)$ & $49,373(12.2)$ & $391,326(8.2)$ & $604,406(8.9)$ \\
2003 & $50(0.2)^{a}$ & $180,393(11.1)$ & $49,357(12.2)$ & $431,763(9.1)$ & $661,564(9.7)$ \\
2004 & $333(1.0)^{a}$ & $169,762(10.5)$ & $45,708(11.3)$ & $500,314(10.5)$ & $716,118(10.5)$ \\
2005 & $447(1.4)^{a}$ & $174,808(10.8)$ & $34,485(8.5)$ & $523,437(11.0)$ & $733,177(10.8)$ \\
2006 & $1267(3.8)^{a}$ & $146,885(9.1)$ & $35,184(8.7)$ & $555,274(11.7)$ & $738,610(10.8)$ \\
2007 & $2156(6.5)$ & $161,223(9.9)$ & $36,358(9.0)$ & $476,168(10.0)$ & $675,905(9.9)$ \\
2008 & $3267(9.9)$ & $131,637(8.1)$ & $37,956(9.4)$ & $461,254(9.7)$ & $634,113(9.3)$ \\
2009 & $9442(28.6)$ & $165,518(10.2)$ & $37,741(9.3)$ & $487,121(10.2)$ & $699,822(10.3)$ \\
2010 & $15,945(48.3)$ & $155,205(9.6)$ & $34,158(8.5)$ & $573,646(12.1)$ & $778,953(11.4)$ \\
Total & $33,041(100)$ & $1,620,796(100)$ & $404,115(100)$ & $4,760,242(100)$ & $6,818,194(100)$ \\
\hline
\end{tabular}

\begin{tabular}{|c|c|c|c|c|}
\hline \multicolumn{5}{|c|}{ Reptile } \\
\hline Year & $\begin{array}{l}\text { Snake (venomous) } \\
\text { number }(\%)\end{array}$ & $\begin{array}{c}\text { Snake (nonvenomous/unknown) } \\
\text { number }(\%)\end{array}$ & $\begin{array}{l}\text { Other reptile } \\
\text { number }(\%)\end{array}$ & $\begin{array}{l}\text { Total reptile } \\
\text { number }(\%)\end{array}$ \\
\hline 2001 & $3056(10.8)^{a}$ & $6609(0.5)$ & $1739(12.7)$ & $11,404(10.8)$ \\
\hline 2002 & $2717(9.6)^{a}$ & $6255(9.9)$ & 2182 (15.9) & $11,153(10.6)$ \\
\hline 2003 & $4189(14.8)^{a}$ & 7334 (11.6) & 1538 (11.2) & $13,062(12.4)$ \\
\hline 2004 & $2791(9.9)$ & $6540(10.3)$ & $1417(10.3)$ & $10,747(10.2)$ \\
\hline 2005 & $3512(12.4)^{a}$ & $6075(9.6)$ & $1206(8.8)$ & $10,793(10.2)$ \\
\hline 2006 & $2009(7.1)^{a}$ & 6783 (10.7) & $1713(12.5)^{a}$ & $10,504(10.0)$ \\
\hline 2007 & $2238(7.9)^{a}$ & 8911 (14.1) & $1127(8.2)^{a}$ & $12,276(11.7)$ \\
\hline 2008 & $2358(8.3)^{a}$ & $5376(8.5)$ & $1120(8.2)^{a}$ & $8854(8.4)$ \\
\hline 2009 & $2619(9.3)^{a}$ & $4149(6.5)$ & $638(4.7)^{a}$ & 7406 (7.0) \\
\hline 2010 & $2762(9.8)^{a}$ & $5369(8.5)$ & $1023(7.5)^{a}$ & 9154 (8.7) \\
\hline Total & $28,250(100)$ & $63,400(90.1)$ & $13,704(100)$ & $105,353(100)$ \\
\hline
\end{tabular}

\footnotetext{
${ }^{a}$ Estimates might be unstable because the number of sample cases was $<20$, weighted estimate $<1200$, or coefficient of variation was $>30 \%$.
} 

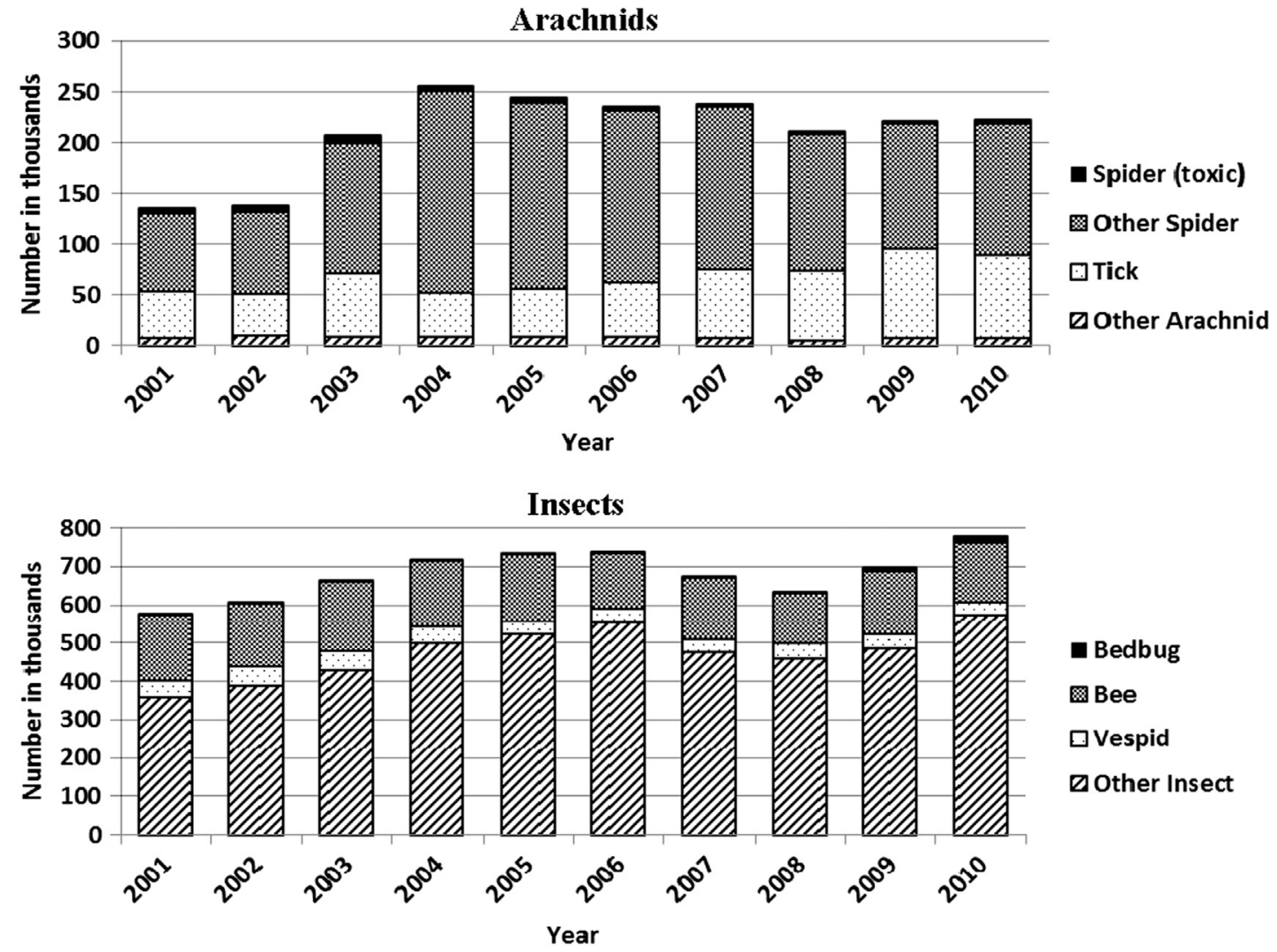

\section{- Bedbug \\ 즘 Bee \\ $\square$ Vespid}

च Other Insect

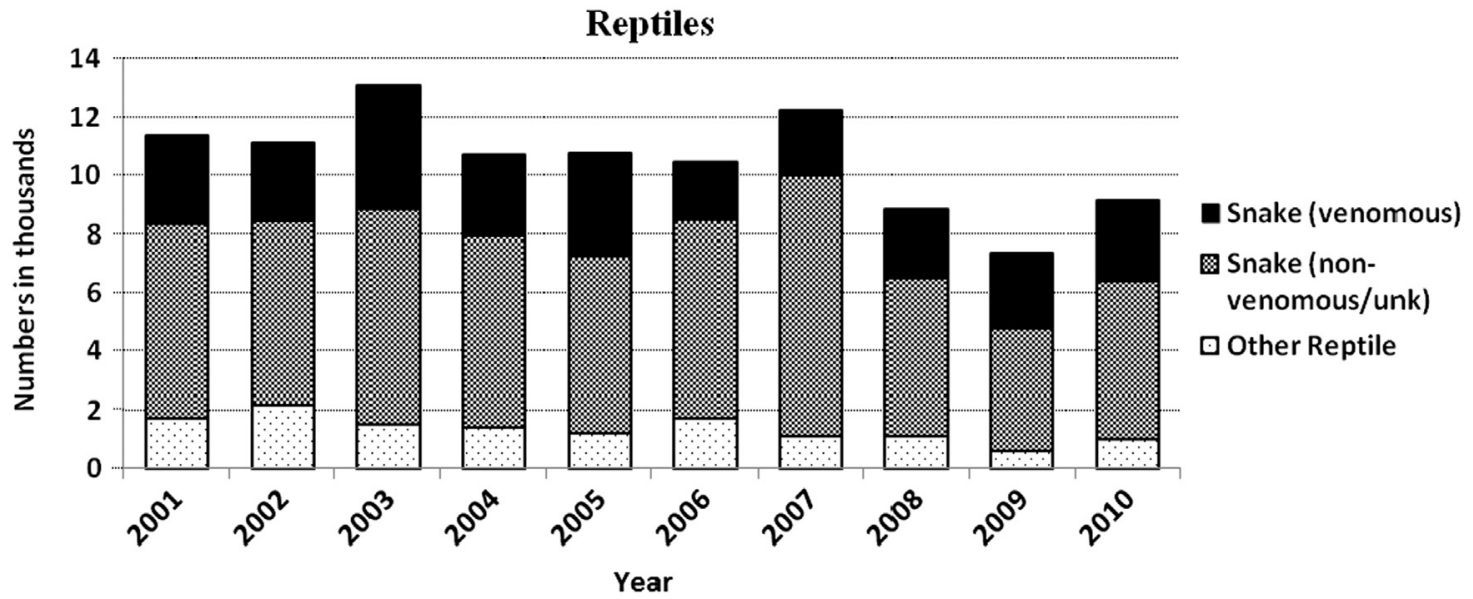

Figure. Estimated number of unintentional nonfatal bite and sting injuries for arachnids, insects, and reptiles by year of treatment.

million birds. ${ }^{18,19}$ Additionally, approximately $11 \%$ to $22 \%$ of US households own specialty or exotic pets. ${ }^{18,19}$

In comparison with overall unintentional nonfatal injuries in which injury rates are higher for males than for females (age-adjusted rates of 10,370 per 100,000 for males and 8681 per 100,000 for females in 2010), this study found similar rates for males and females treated in EDs for noncanine injuries. ${ }^{17}$ The risk of noncanine bite or sting injury was greatest during the summer months, usually the season more people are active out of doors, thus increasing their exposure to wildlife. This seasonal pattern has been seen previously in other animal bite studies. $^{13,20}$ Injuries were mostly on the extremities, similar to previous reports. ${ }^{13}$

The severity of the injury was measured in this study based on whether the person was treated in the ED and released or treated and then admitted to the hospital or transferred for specialized medical care. Only $1.8 \%$ of patients who were treated in the ED for noncanine bite or sting injuries were hospitalized or transferred compared 
with $6.0 \%$ for all unintentional, nonfatal injuries during 2001 to 2010. Although not assessed in this study, certain animal bites or sting injuries are more likely to lead to hospitalizations. In a previous study of US ED visits for animal bites or stings, 3.2\% of patients with anaphylactic symptoms were hospitalized. ${ }^{13}$ Hospitalization from venomous snakebites ranged from $58.4 \%$ of venomous snakebite victims in 2001 to 2004 to $27.7 \%$ in a study from 2006 to 2008 . $^{12,13}$

Treatment of nonfatal bite and sting injuries are costly to society. The estimated annual total lifetime medical and work loss (eg, wages and fringe benefits and unpaid household work) ${ }^{17}$ for unintentional noncanine injury was $\$ 5,674,230,000$. For unintentional canine injury treated in the ED, the estimated total lifetime medical and work loss cost was $\$ 1,845,681,000$. Collectively, the estimated combined total lifetime medical and work loss cost for all unintentional animal-related bite or sting injuries was $\$ 7,519,911,000$. These costs do not include pain and suffering, loss of quality of life, litigation, and other costs to family members and do not include cases held for observation or cases who left the ED without being treated.

An increasing number of bite or sting injuries from ticks and bedbugs, especially for 2009 and 2010, were observed in our trend analysis. The number of tick bites increased from the 40,000 to 45,000 range in 2001 to 2002 to 80,000 to 89,000 range in 2009 to 2010 . Of interest is that during that general time frame, the number of cases of tick-associated diseases also increased. ${ }^{21}$ Information on tick removal and tick-borne illness is available on the CDC website (http://www.cdc. gov/ticks). The increase in the number of tick bites reported and treated may be related to a variety of factors, including better public awareness, increased range of ticks, increased tick population, and humans frequenting areas with ticks. ${ }^{22,23}$

Bedbug bites appears to be an emerging issue. ${ }^{24} \mathrm{~A}$ survey among 1000 pest control companies reported that 95\% of respondents in the United States and 98\% in Canada reported encountering bedbug infestations in the previous year compared with $25 \%$ of respondents from both countries before $2000 .^{25}$ There have been several recent adverse reactions in humans from pesticides used to control bedbugs. ${ }^{26}$ Bedbugs, however, are not known to spread disease. Information about preventing bedbug infestation is also available on the CDC website (http:// www.cdc.gov/parasites/bedbugs/).

\section{LIMITATIONS}

The NEISS-AIP provides national estimates and does not include state or local estimates. This limitation is evident among species of animals whose distribution and incidence vary across the country. In addition, there is much disagreement regarding identification of certain species, especially among the spiders. Poisonous spider bites may be misdiagnosed in certain areas where the species is not known or likely to be present based on current surveys of spider populations. ${ }^{27,28}$ In many cases, the person assumes they were bitten if they have a rash or lesion, even though they may not have actually seen an insect or arachnid present. This is evident in our study, with $42.7 \%$ of bite and sting injuries classified as resulting from an unspecified insect. Information on circumstances surrounding the event, location where the event occurred, and detail in the narrative is often limited. Information on prior insect allergies was not collected in this study but would be useful information to know in cases of anaphylaxis. In addition, cases that were treated in an urgent care clinic or physician's office, and those who were self-treated or who went untreated were not included in this study; thus, the total extent of bite and sting injuries is undercounted. Also, information was not obtained on whether a bite or sting injury resulted in a wound infection or whether a person developed a zoonotic disease.

\section{Conclusions}

From 2001 to 2010, an average of more than 1 million unintentional noncanine bite or sting injuries were treated in US hospital EDs annually. Increases in the number of ED visits for tick and bedbug bite injuries were notable during this 10 -year study period. Treating bite and sting injuries continues to consume substantial healthcare resources. Preventing injuries can be accomplished by avoiding exposure to unfamiliar and wild animals, using repellents, choosing and handling pets appropriately, and wearing clothing that protects the skin. Although preventing these injuries would be the first line of defense, considerable cost-savings might also be achieved through public education on immediate first aid and on the warning signs and symptoms that indicate a need for professional emergency care. Dissemination of guidelines for treating bite and sting injuries may reduce the number of injuries treated in EDs.

\section{References}

1. American Veterinary Medical Association. A community approach to dog bite prevention. J Am Vet Med Assoc. 2001;218:1732-1749.

2. Centers for Disease Control and Prevention. 2009 national dog bite prevention week. Atlanta, GA. Available at: www.cdc.gov/HomeandRecreationalSafety/Dog-Bites/bite prevention.html. Accessed January 25, 2013. 
3. Meints K, de Keuster T. Brief report: Don't kiss a sleeping dog: the first assessment of "The Blue Dog" bite prevention program. J Pediatric Psychol. 2009;34: 1084-1090.

4. Gilchrist J, Sacks JJ, White D, Kresnow MJ. Dog bites: still a problem? Inj Prev. 2008;14:296-301.

5. Sacks JJ, Kresnow MJ, Houston B. Dog bites: how big a problem? Inj Prev. 1996;2:52-54.

6. Centers for Disease Control and Prevention (CDC). Nonfatal dog bite-related injuries treated in hospital emergency departments-United States, 2001. MMWR Morb Mortal Wkly Rep. 2003;52:605-610.

7. Quirk JT. Non-fatal dog bite injuries in the U.S.A., 20052009. Public Health. 2012;126:300-302.

8. Centers for Disease Control and Prevention (CDC). Nonfatal fall-related injuries associated with dogs and catsUnited States, 2001-2006. MMWR Morb Mortal Wkly Rep. 2009;58:277-281.

9. Langley RL. Animal bites and stings reported by United States Poison Control Centers, 2001-2005. Wilderness Environ Med. 2008;19:7-14.

10. Langley RL. Animal-related fatalities in the United Statesan update. Wilderness Environ Med. 2005;16:67-74.

11. Forrester JA, Holstege CP, Forrester JD. Fatalities from venomous and nonvenomous animals in the United States (1999-2007). Wilderness Environ Med. 2012;23: 146-152.

12. Langley RL. Animal-related injuries resulting in emergency department visits and hospitalizations in the United States, 2006-2008. Hum Wildlife Interact. 2012;6: 123-136.

13. O'Neil ME, Mack KA, Gilchrist J. Epidemiology of noncanine bite and sting injuries treated in U.S. emergency departments, 2001-2004. Public Health Rep. 2007;122: 764-775.

14. Quinlan KP, Thompson MP, Annest JL, et al. Expanding the National Electronic Injury Surveillance System to monitor all nonfatal injuries treated in US hospital emergency departments. Ann Emerg Med. 1999;34:637-645.

15. Vyrostek SB, Annest JL, Ryan GW. Surveillance for fatal and non-fatal injuries-United States, 2001. MMWR Surveill Summ. 2004;53:1-57.

16. Schroeder T, Ault K. NEISS All Injury Program: Sample Design and Implementation. Washington, D.C.: U.S. Consumer Product Safety Commission; 2001.
17. Centers for Disease Control and Prevention. Injury Prevention and Control: Data and Statistics (WISQARS). Available at: www.cdc.gov/injury/wisqars. Accessed February $15,2013$.

18. American Veterinary Medical Association. U.S. Pet Ownership \& Demographics Sourcebook (2012). Available at: https://www.avma.org/KB/Resources/Statistics/Pages/ Market-research-statistics-US-Pet-Ownership-Demogra phics-Sourcebook.aspx. Accessed January 25, 2013.

19. American Pet Products Association. 2011/2012 APPA National Pet Owners Survey. Available at: http://www. americanpetproducts.org/pubs_survey.asp. Accessed January 25, 2013.

20. Raghavan M. Fatal dog attacks in Canada, 1990-2007. Can Vet J. 2008;49:577-581.

21. Centers for Disease Control and Prevention. Ticks. Available at: http://www.cdc.gov/ticks/index.html. Accessed January 25, 2013.

22. Rosenthal M. Tick populations to explode in 2013: experts predict tick populations will increase dramatically in many areas of the United States. Veterinary Practice News. March 28, 2013. Available at: http://www.veterinarypracti cenews.com/vet-cover-stories/tick-populations-to-explode. aspx. Accessed June 5, 2013.

23. Estrada-Peña A. Increasing habitat suitability in the United States for the tick that transmits Lyme disease: a remote sensing approach. Environ Health Perspect. 2002;110: 635-640.

24. Doggett SL, Dwyer DE, Peñas PF, Russell RC. Bed bugs: clinical relevance and control options. Clin Microbiol Rev. 2012;25:164-192.

25. Benac N. Bedbug bites becoming bigger battle. CMAJ. 2010;182:1606.

26. Centers for Disease Control and Prevention (CDC). Acute illnesses associated with insecticides used to control bed bugs-seven states, 2003-2010. MMWR Morb Mortal Wkly Rep. 2011;60:1269-1274.

27. Vetter RS. Arachnids misidentified as brown recluse spiders by medical personnel and other authorities in North America. Toxicon. 2009;54:545-547.

28. Vetter RS. Arachnids submitted as suspected brown recluse spiders (Aranea:Sicariidae): Loxosceles spiders are virtually restricted to their known distributions but are perceived to exist throughout the United States. $J$ Med Entomol. 2005;42:512-521. 